\title{
Celnestato
}

\section{Os desafios da gestão editorial no contexto da ciência aberta}

\author{
Patrícia Pedri \\ Mestranda; Universidade Federal de Alagoas, Maceió, AL, Brasil; \\ patriciapedri@gmail.com \\ Ronaldo Ferreira Araujo \\ Doutor; Universidade Federal de Alagoas, Maceió, AL, Brasil; \\ ronaldfa@gmail.com
}

SILVEIRA, Lúcia da; SILVA, Fabiano Couto Corrêa da (Orgs.). Gestão editorial de periódicos científicos: tendências e boas práticas. Florianópolis, SC: Universidade Federal de Santa Catarina, 2020. 226 p.

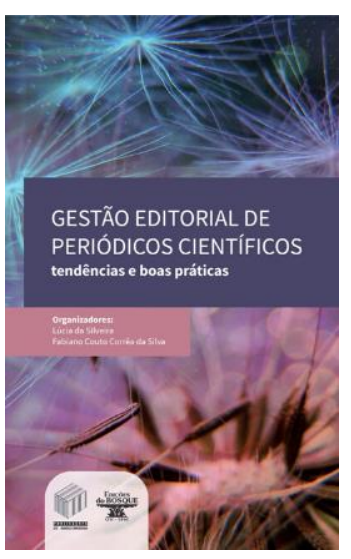

Resumo: Resenha do livro Gestão editorial de periódicos científicos: tendências e boas práticas organizado por Lúcia da Silveira e Fabiano Couto Côrrea da Silva. A coletânea apresenta processos, ferramentas e reflexões acerca das políticas editoriais consoantes a disseminação da informação científica.

Palavras-chave: Periódicos científicos. Gestão editorial. Disseminação da informação.

Os periódicos consistem no principal canal de publicação dos resultados das pesquisas científicas. Além de endossá-las por meio de um sistema de avaliação por pares, consistem também em um importante veículo de disseminação desse tipo de informação dentro e fora da comunidade científica.

Atentos à demanda social de ampliação do acesso, de mais agilidade, ética e transparência na produção e publicação científica, Lúcia da Silveira e Fabiano Couto Côrrea da Silva lançaram em 2020 uma coletânea de textos sob o título de Gestão editorial de periódicos científicos: tendências e boas práticas, em formato digital e disponível na web. 
Os organizadores tiveram o cuidado de iniciar cada um dos sete capítulos do livro com a ilustração das fases da florescência do dente-de-leão, planta conhecida pelas suas sementes que se espalham facilmente com a mais leve brisa. A menção à planta, que também estampa a capa do livro, revela a intenção dos organizadores de apresentar novas possibilidades de ampliar a disseminação do conhecimento científico, tal qual às sementes voadoras do dente-de-leão.

No prefácio da obra, Ernest Abadal aponta as transformações e desafios das revistas científicas. A digitalização, o acesso aberto e a ciência aberta foram apresentados como os grandes marcos das transformações dos periódicos nos últimos 30 anos. E entre os desafios, o monopólio do fator de impacto na avaliação das publicações ganha destaque. Desse modo, Abadal pavimenta o caminho para as reflexões que se aprofundam nos capítulos seguintes.

O primeiro capítulo "Gestão editorial: tendências e desafios na transição para a ciência aberta" de Solange Maria dos Santos e Lilian Nassi-Calò apresenta os dados abertos, periódicos de dados, preprints e revisão por pares aberta como algumas das principais tendências e práticas editoriais alinhadas com o movimento da ciência aberta.

As autoras expõem de forma sistemática as definições, exemplos, experiências e também as vantagens e desvantagens dessas tendências. E, em um tom conciliador, propõem práticas que atendam tanto às necessidades específicas da política editorial de cada periódico, quanto à ampliação da transparência na elaboração, avaliação, disseminação e uso do conhecimento científico. Por fim, Santos e Nassi-Caló, alertam para a necessidade de criar condições para melhor implementação dessas práticas, pois não há infraestrutura em âmbito nacional para compartilhamento de dados, tampouco as agências de fomento e os sistemas de avaliação de pesquisa consideram preprints ou citações de artigos de dados.

No contexto de dados abertos, o capítulo “Gestão de dados científicos para periódicos" de Fabiano Couto Corrêa da Silva apresenta os benefícios da gestão de dados científicos, bem como algumas iniciativas e recomendações sobre o uso apropriado de recursos para o armazenamento e disseminação de dados.

O autor defende que os dados das pesquisas científicas devem ser citáveis a fim de sustentar o seu compartilhamento e também demonstrar a sua relevância 
para as pesquisas. Para tanto, dados e metadados devem usar identificadores persistentes para serem recuperáveis em uma variedade de formatos; usar vocabulário aberto e bem definido para serem interoperáveis e; garantir que possam ser processados e verificados por máquinas a fim de serem reutilizáveis. Mesmo com o grande desconhecimento da comunidade científica sobre como realizar o armazenamento e acesso de dados, Silva recomenda que as escolhas editoriais sejam sempre na perspectiva da ciência aberta, possibilitando um ciclo de retroalimentação beneficiando a rede da produção científica e, principalmente a sociedade.

Esse desconhecimento também alimenta uma das maiores preocupações da comunidade científica que são os direitos autorais não só dos dados, mas também no contexto do acesso aberto. Nesse sentido, o capítulo "Direitos de autor e licenças Creative Commons para periódicos científicos de acesso aberto" de Fabio Lorensi Canto, Enrique Muriel-Torrado e Adilson Luiz Pinto, apresenta de forma muito elucidativa, uma síntese do direito autoral brasileiro e também recomendações sobre políticas de cessão do direito do autor e adoção de licença Creative Commons.

Dado o predomínio do financiamento público nas pesquisas, os autores alertam que a informação científica não deve ser tratada como um bem ou serviço sujeito às leis de livre mercado. E apontam a dissonância entre o que foi definido como acesso aberto e os atuais modelos de negócio de periódicos científicos, que muitas vezes usam o acesso aberto com a finalidade de manter o domínio do mercado científico editorial das empresas multinacionais. $\mathrm{O}$ capítulo ainda traz reflexões relevantes acerca dos direitos autorais no contexto do acesso aberto e apresenta as vantagens e limites das licenças Creative Commons. Os autores alertam que, mesmo sendo uma empresa sem fins lucrativos que incentiva a criação, compartilhamento e o uso de obras gratuitas; a adoção imprudente das suas licenças pode descaracterizar a publicação de acesso aberto. Pois, embora essas iniciativas sejam aliadas à ciência aberta, ao promover a produção coletiva podem também deixar brechas para apropriação privada dessas informações produzidas coletivamente (ALBAGLI, 2014). 
$\mathrm{Na}$ direção de ampliar o acesso às publicações científicas, o capítulo "Como pensar a acessibilidade em artigos de periódicos: tendências em design universal para pessoas com deficiência visual" de José Carlos Rodrigues e Salete Cecília de Souza, discute os processos de produção de textos eletrônicos em formatos acessíveis para assegurar a leitura por pessoas com deficiência visual dos textos publicados em portais de periódicos das universidades brasileiras.

Os autores apresentam conceitos essenciais sobre a deficiência visual, a acessibilidade (eixos e trajetória legal), e, especialmente sobre as tecnologias assistivas que consistem em leitores e ampliadores de telas utilizados por pessoas com cegueira ou baixa visão para acessarem as informações por meio de um computador com resposta sonora ou ampliação de caracteres. Todavia alertam que, em sua maioria os documentos publicados nos ambientes virtuais ainda não estão em formato acessível, tornando essas tecnologias ineficazes para o acesso à informação. Segundo Rodrigues e Souza o desenvolvimento de portais de periódicos deve ser pautado pelos princípios do design universal, padrões técnicos e boas práticas para ampliar a acessibilidade. Defendem ainda que é fundamental a convivência e a presença das pessoas com deficiência visual nos processos de planejamento, produção e avaliação dos portais para a qualificação de toda a cadeia da produção acadêmica.

O capítulo "Ferramentas de gestão editorial para periódicos em acesso aberto" de Juliana Fachin, Lúcia da Silveira e Diego Abadan, indicam boas práticas de gestão do fluxo editorial de acesso aberto e ferramentas de acesso livre ou com versões gratuitas de fácil aplicação e entendimento que visam a ajudar a sistematizar e organizar o processo de editoração.

Essas práticas e ferramentas são apresentadas de forma bastante ilustrativa em nove categorias do trabalho de publicação científica: planejamento editorial, fluxo editorial, publicação de fascículos, divulgação de periódicos, indexação de periódicos, análise de métricas, acompanhamento das inovações, reavaliação das estratégias e preservação de dados. O sistema de publicação do Open Journal Systems (OJS) ganhou uma seção própria no capítulo, onde os autores evidenciam de forma mais detalhada as diferenças e semelhanças entre recursos das versões 2.4.8 e 3.1, destacando a interface visual responsiva, funcionalidades do painel de 
controle e plugins da nova versão. Todavia, ao apontar os limites de cada ferramenta, os autores atentam para a necessidade de planejamento e organização para que a ferramenta selecionada seja a mais adequada para as necessidades de cada periódico.

Vale ressaltar que no Brasil os periódicos científicos em sua maioria são mantidos por universidades públicas, daí a importância da criação e boa gestão dos portais de periódicos, que são um centro de informações de editoração de periódicos.

Nesse sentido o capítulo "Dez boas práticas para portais de periódicos" de Lúcia da Silveira, Gildenir Carolino Santos e Claudia Oliveira de Moura Bueno apresenta orientações mínimas para a realização da gestão de portais de periódico. Os autores acreditam que investir na criação e manutenção do portal de periódicos institucional é atender a uma das dimensões da ciência aberta, além de melhorar a qualidade dos periódicos associados.

O capítulo destaca a definição, as funções e caraterísticas educativa, tecnológica, social e política dos portais de periódicos. Além, é claro, de apontar dez boas práticas de gestão e conselhos dos coordenadores de portal, a partir das experiências adquiridas pelos autores na gestão dos portais de periódicos institucionais da UNICAMP, UFG e UFSC. Essas práticas abordam: o conselho consultivo; a infraestrutura de equipe; a institucionalização; a gestão e planejamento; a formação; a inclusão, permanência e exclusão dos periódicos; a padronização; as estatísticas; a tecnologia e segurança; além da divulgação científica.

Aliás, a divulgação científica, por ser considerada tão importante quanto as atividades de produção e publicação, é tema do último capítulo "Marketing científico digital e práticas de comunicação e divulgação de portais de periódicos: notas de uma primeira incursão" de Ronaldo Ferreira de Araújo, Celsiane Aline Vieira Araújo, Sergio Dias Cirino, Marcella Ximenes de Mello Boehler e Renata Kelly de Arruda. $O$ texto reflete sobre a emergência do marketing científico digital nos portais de periódicos dando uma atenção especial à presença on-line das revistas como estratégia de promoção e divulgação científica. 
O capítulo também ilustra a presença e atuação on-line na seleção, escolha e uso de canais, conteúdos e estratégias desenvolvidas no Portal Periódicos de Minas, no Portal de Periódicos UFSC e no Portal de Periódicos da Friocruz. Os autores ainda destacam a necessidade da curadoria de conteúdo digital a fim de criar estratégias de produção de conteúdo e uso adequado de canais de mídias sociais, gerando um bom desempenho das revistas constatado em indicadores alternativos como a altimetria.

Nessa obra percebe-se que o atual desenvolvimento tecnológico e os avanços da ciência aberta, ainda que com um longo caminho a percorrer, imprimem mudanças no modelo de investigação e publicação cientifica. E, nesse sentido, os textos reunidos nessa coletânea promovem reflexões teóricas e indicações práticas fundamentais na adequação do fluxo editorial dos periódicos às demandas atuais.

Talvez com um olhar mais severo, possa ser observada a ausência de um capítulo exclusivo para a revisão por pares aberta, ainda que o tema tenha sido tratado com propriedade no primeiro capítulo. Afinal a abertura do processo avaliação por pares consiste em um dos eixos estratégicos da ciência aberta, juntamente com o acesso e dados abertos (SPINAK, 2018), além de constar como um dos desafios para as revistas científicas, mencionados por Abadal no prefácio.

Embora os capítulos sejam a princípio independentes, é perceptível a intenção dos organizadores em ordenar os textos e orientar os autores na construção de um encadeamento de ideias síncronas a fim de reforçar a necessidade de boas práticas editoriais que contribuam para a ciência aberta.

Portanto, o livro em seu pioneirismo preenche uma lacuna acerca das tendências e boas práticas na gestão de periódicos e vale como um guiaconselheiro para gestores de portais e editores de periódicos, pesquisadores, bibliotecários, divulgadores e jornalistas científicos comprometidos com a democratização do conhecimento científico.

Em resumo, a obra fortalece a ideia de que, assim como o de dente-de-leão necessita desenvolver uma densa rede de raízes para desenvolver e espalhar suas sementes, a informação científica precisa de infraestrutura para ser disseminada, com políticas (públicas e editoriais) e práticas consoantes com o movimento de 
ciência aberta. Afinal, tal qual o dente-de-leão, o conhecimento é raiz, flor e semente.

\title{
Referências
}

SILVEIRA, Lúcia da; SILVA, Fabiano Couto Côrrea da. Gestão editorial de periódicos científicos: tendências e boas práticas. - 1. ed. - Florianópolis: BU Publicações/UFSC : Edições do Bosque/UFSC, 2020.

SPINAK, Ernesto. Sobre as vinte e duas definições de revisão por pares aberta... e mais. SciELO em Perspectiva, 28 fev. 2018. Disponível em: https://blog.scielo.org/blog/2018/02/28/sobre-as-vinte-e-duas-definicoes-derevisao-por-pares-aberta-e-mais/. Acesso em: 10 set. 2019.

ALBAGLI, Sarita. Ciência Aberta em questão. In: Seminário Internacional Ciência Aberta, Questões Abertas, Rio de Janeiro, 2014. Trabalho apresentado...Rio de Janeiro: Liinc; IBICT; OKF; Unirio, 2014. Disponível em: http://www.cienciaaberta.net/encontro2014/ . Acesso em: 1 set 2014.

\section{The challenges of editorial management in the open science context}

\begin{abstract}
This critical review talks about the book 'Editorial management of scientific journals: trends and good practices' organized by Lúcia da Silveira and Fabiano Couto Côrrea da Silva. The collection presents processes, tools and reflections about editorial policies according to the dissemination of scientific information.
\end{abstract}

Keywords: Academic journals; Editorial management; Dissemination of information.

Recebido: 20/11/2020

Aceito: 25/01/2021

\section{Declaração de autoria}

Concepção e elaboração do estudo: Patrícia Pedri, Ronaldo Ferreira de Araujo Coleta de dados: Patrícia Pedri

Análise e interpretação de dados: Patrícia Pedri, Ronaldo Ferreira de Araujo Redação: Patrícia Pedri, Ronaldo Ferreira de Araujo

Revisão crítica do manuscrito: Patrícia Pedri, Ronaldo Ferreira de Araujo 
Os desafios da gestão editorial no contexto da ciência aberta

Patrícia Pedri e Ronaldo Ferreira Araujo

\section{Como citar}

PEDRI, Patrícia; ARAUJO, Ronaldo Ferreira de. Os desafios da gestão editorial no contexto da ciência aberta. Em Questão, Porto Alegre, v. 27, n. 2, p. 449456, abr./jun. 2021.

Doi: http://dx.doi.org/10.19132/1808-5245272.449-456 